Article

\title{
Development of a Standard Brownfield Definition, Guidelines, and Evaluation Index System for Brownfield Redevelopment in Developing Countries: The Case of Pakistan
}

\author{
Naveed Ahmad ${ }^{1, *(\mathbb{D})}$, Yuming Zhu ${ }^{1, *}$, Muhammad Ibrahim ${ }^{2}$, Muhammad Waqas ${ }^{3} \mathbb{D}$ and \\ Abdul Waheed ${ }^{1}$ \\ 1 School of Management, Northwestern Polytechnical University, 127 West Friendship Road, Beilin District, \\ Xi'an 710072,China; waheed_2506@mail.nwpu.edu.cn \\ 2 Department of Engineering Sciences, Institute of Business Management, Korangi Creek, Karachi, \\ Sindh 74900, Pakistan; muhammad.ibrahim@iobm.edu.pk \\ 3 School of Economics and Management, Chang'an University, Second Ring Road, Xi'an 710072, China; \\ waqasalyani23@chd.edu.cn \\ * Correspondence: naveedahmad@mail.nwpu.edu.cn (N.A.); zym1886@nwpu.edu.cn (Y.Z.)
}

Received: 1 November 2018; Accepted: 19 November 2018; Published: 22 November 2018

check for updates

\begin{abstract}
Brownfield is post-industrial soil resulting from different anthropogenic activities and located in urban centers of cities. Due to the scarcity of urban land and the complexity of renovating old cities, and considering that brownfield research in Pakistan is still in its infancy, defining and evaluating brownfield is necessary for solving environmental issues and promoting sustainable development. Therefore, this study aims to develop a pioneer consensus-based brownfield definition, guidelines, and an evaluation index system to evaluate brownfield redevelopment in Pakistan. Initially, a comprehensive literature review was performed to gather key elements of brownfield definitions and create an evaluation index system. These indicators were further evaluated by different experts through the Delphi Method to develop a final questionnaire. Then, data were collected from relevant stakeholders. An illustrative example using three ideal schemes (housing society, eco-industrial park, and commercial market) is described to apply the evaluation index system. A new methodology combining Triangular Fuzzy Numbers (TFNs) and Grey Relational Analysis (GRA) was introduced to assess three ideal schemes. Finally, a pioneer brownfield definition, guidelines, and evaluation index system for brownfield redevelopment were developed, and a further index system was verified through an illustrative example. The standard brownfield definition, guidelines, and established index system is based on the Pakistani context. Due to changes in rules and regulation, and different land characteristics, these findings cannot be generalized to all developing countries. Therefore, further studies must validate the results in their own context. This study will foster brownfield redevelopment implementation in Pakistan and promote sustainable development.
\end{abstract}

Keywords: brownfield; brownfield redevelopment; sustainable development; definition; guidelines; evaluation index system

\section{Introduction}

Brownfield is often composed of degraded soils with a potential availability of contaminants that contribute to extensive pollution of the environment. There are more than 500,000 brownfield sites in the USA alone that need to be redeveloped, with an approximate clean-up cost of $\$ 650$ million. Almost 800,000 sites have been perceived as brownfield in Europe, with an estimated remedial cost of about 
115 billion euros. Generally, brownfield is considered post-industrial sites resulting from different anthropogenic activities and located in urban centers of cities. The scarcity of urban land, due to environmental constraints, means environmental policies have become stringent [1,2]. Redeveloping brownfield can support urban development and decrease the massive pressure on greenfield. However, due to the existence of contaminants and poor soil condition, redevelopment becomes complex [3]. Different kinds of brownfield sites face different problems; while some can be remediated easily, many others are vacant and underused for a long time. In developed countries, post-industrial is the common term used for brownfield of every type from contaminated industrial sites to former factory sites, usually located in declining areas of the city [4]. Due to the short history of industrialization in Pakistan, there is a low ratio of brownfield, but still, plenty of brownfield sites can be found in the form of former factories, buildings, railway areas, military areas, coalfields, and semi-urban and agricultural areas.

Pakistan is a developing country seventh in terms of world population, with 201 million residents. It is ranked the second largest economy in South Asia, with a GDP of about \$988.2 million [5]. Environmental pollution and soil degradation are major problems in Pakistan, and the perception of brownfield is negative. In September 2015, the United Nations (UN) adopted 17 sustainable development goals (SDGs) to transform the world by 2030 [6]; these include a specific goal, SDG 11, for sustainable cities and communities (make cities and human settlements inclusive, safe, resilient, and sustainable). Considering these goals, brownfield redevelopment seems to be an effective approach to make Pakistani cities more sustainable. However, in 2017, Pakistan was ranked 122nd in the sustainable development goals (SDGs) global index, securing a score of 55.6, which is an alarming situation [7]. Brownfield is one of the major hurdles to the successful implementation of sustainable development and is contributing towards environmental pollution and also disturbing environmental integrity [8].

Compared to developed countries, there is little awareness of brownfield issues in Pakistan. Redeveloping brownfield for environmental sustainability is fairly limited and did not get public recognition. In fact, there is hardly any literature on this issue, and no official definition of brownfield is present. However, brownfield issues are capturing more attention in Pakistan due to different factors: Government implementation of a new solid waste and pollution management policy was introduced in 2016 under Sections 13 and 14 of the Pakistan Environmental Protection Act, 1997, named "Draft hazardous waste and hazardous substances rules (DHWHSE)," which noted the potential benefits associated with brownfield, such as economic value and improvement in social sustainability. DHWHSE (2016) focuses on overcoming financial dilemmas for the recovery of brownfield and to clean up hazardous substances. Moreover, it emphasizes how to deal with other critical issues associated with different kinds of brownfield, e.g., urban brownfield, former military areas, railway land, and post-industrial sites. The Provincial Sustainable Development Fund Rules (PSDFR) highlight the need to develop land pollution database, reduce ownership constraints, and establish a collaborative financial mechanism between federal, provincial, and local environmental authorities [9].

The abovementioned environmental and land policies are major driving forces that promote brownfield redevelopment in Pakistan. To reach a good position in the global SDGs index, it is necessary to take advantage of the plentiful benefits associated with brownfield and adopt it as a land use strategy in Pakistan. Therefore, an important first step is to understand these former sites, to foster the transformation of brownfield into greenfield, which is not easy to redevelop, is to define brownfield and develop a mechanism to evaluate brownfield in the Pakistani context. Brownfield is an evolving issue in Pakistan. Parties aiming to redevelop brownfield have to deal with certain problems. To understand site characteristics and different divisions (vacant land, underused land, contaminated land, hazardous land, abandoned land, etc.) of brownfield, there should be consistency in developing new procedures and a framework to deal with brownfield redevelopment. Considering this situation, a well-recognized and consensus-based brownfield definition is essential to avoid misunderstanding and develop a common set of words for every person involved in the brownfield redevelopment 
process [10]. More specifically, a lack of brownfield literature in Pakistan is also a stepping stone to developing a brownfield definition, guidelines, and an index system.

In fact, the poor evaluation and feasibility of brownfield reveal a major issue for those involved in the redevelopment process, which is related to understanding different site characteristics and divisions (vacant land, underused land, contaminated land, hazardous land, abandoned land, etc.) in order to achieve consistency that enables us to develop new procedures to better deal with degraded soil $[10,11]$. Therefore, it is necessary to bring all stakeholders to the table to develop a consensus-based brownfield definition to evade misunderstanding, but also to develop a common concept among all participants in the redevelopment process. Moreover, there is an increasing concentration on brownfield redevelopment due to the following factors: the introduction of a new environmental policy in 2016 (a national policy on solid waste management), scarcity of urban land in metropolitan cities, negative perception about brownfield, and urban sustainability issues.

In the last two decades, various evaluation approaches and index systems have been proposed to evaluate urban brownfield redevelopment including a life cycle inventory model [12], the rough set approach [1], the multi-attribute decision method (MADM) and analytical hierarchy process (AHP) [13,14], fuzzy real options [15], multi-criteria genetic algorithm [16], multi-hierarchical grey evaluation modeling [17], system dynamics model [18], general organizational logic model [19], GIS spatial analysis [20], spatial explicit algorithm assessment [21], grey cluster methods [22], emergy-based assessment [11], and structural equation modeling [23,24]. However, all these approaches were used to evaluate brownfield in developed countries, whereas less attention has been paid in developing countries like Pakistan. Zhu et al. integrated methodologies of fuzzy grey theory and data envelopment analysis to establish a project management theory-based framework to deal with brownfield issues in China [25]. However, this established framework is not validated; its application needs to be verified in different contexts, and there is a need for an evaluation index system.

Considering the studies mentioned above, it can be said that different countries adopt different practices to deal with brownfield and promote sustainable development. Due to differences in rules and regulations and the level of economic development, as well as different brownfield characteristics and levels of brownfield redevelopment adoption, the definition, guidelines, and evaluation index system developed by different developed countries cannot be generalized to developing countries. Therefore, this study tries to fill the gap by developing a brownfield definition, guidelines, and an index system combining Triangular Fuzzy Numbers (TFNs) and Grey Relational Analysis (GRA).

Therefore, this study empirically aims:

- To develop a pioneer brownfield definition in the Pakistani context

- To develop guidelines for brownfield redevelopment implementation

- To develop an index system to evaluate brownfield redevelopment in Pakistan using a hybrid approach of GRA and TFNs.

This study contributes significantly to the literature in many perspectives. First, the established brownfield definition and guidelines can work as a foundation to promote brownfield redevelopment in Pakistan. Second, the evaluation index system for brownfield redevelopment will provide support for better decision-making considering different alternatives of redevelopment. Third, this study will be useful to help relevant departments with developing effective urban land use policies.

The study is organized as follows: Section 2 gives an overview of the relevant literature, Section 3 explains the research methodology and solution methodology; Section 4 presents the results and discussion; and Section 5 provide concluding remarks, research implications, and future research directions.

\section{Literature Review}

This section provides details about the theoretical framework, and relevant literature on BR, brownfield definitions, and the integrated methodology of TFNs and GRA. 


\subsection{Theoretical Framework}

The stakeholder theory has its foundation in the organizational context and deals with moral and ethical values in the organization. The application of stakeholder theory to environmental issues is limited. Therefore, this study utilizes this theory to define and evaluate brownfield sites in the Pakistani context. The word stakeholder was initially introduced by Stanford Research Institute in 1963 and can be defined as "Any group who supports organization to cease to exit from the market." Freeman presented the stakeholder theory in 1984 and defined the term stakeholder as "Any group or individual that can affect or is affected by the accomplishment of organizational goals."

The brownfield redevelopment process poses different stakeholders. These can be different parties involving in decision-making about the brownfield redevelopment process, it is important to protect the right of each stakeholder to gain sustainable and desired results in the redevelopment process. Different stakeholders in the brownfield redevelopment process may include:

\subsubsection{Government Bodies}

The government is an important stakeholder in the brownfield redevelopment process due to having better information than other stakeholders. Different issues like information asymmetry and externalities make government more significant, and government supervision is essential to cope with such issues. The majority stake of the government is due to the following benefits: environmental quality improvement, improvement in infrastructure development, increase in employment, and tax and revenue collection.

\subsubsection{Investors and Developers}

Investors are the major source of capital, which is necessary to execute redevelopment activities and transform brownfield into sustainable sites for economic development.

\subsubsection{Communities}

In the market economic system, communities, brownfield landowners, and local citizens are also important parties. Ownership transfer for proper compensation is a major concern of owners. Treatment of pollutants and health risks are the issues focused om by communities.

\subsubsection{Non-Governmental Organizations (NGOs)}

NGOs aim to protect society and work for the public welfare. Environmental sustainability, healthy lifestyle, and improved educational infrastructure are the major issues of concern for NGOs.

\subsection{Brownfield Redevelopment}

The existence of brownfield not only creates environmental pollution and hazardous substances, but also results in a shortage of urban land, increasing crime, and economic pressure. Therefore, redeveloping brownfield should be given special consideration when implementing sustainable development. The main goal of brownfield redevelopment is to reduce urban sprawl, develop space for productive activities, and improve social image and the provision of public facilities without compromising quality of life. The European Urban Environment Brownfield Sustainable Development Plan (EUEBSDP) demonstrates that the sustainable use of brownfield land can decrease the pressure on greenfield and provide a solution to the shortage of urban land.

Moreover, it satisfies the needs of human beings by ensuring environmental, economic, and social sustainability. Dixon [26] suggests that brownfield redevelopment is one of the major sources of environmental sustainability as it reduces environmental pollution, utilizes renewable resources available at the site, and protects biodiversity and the natural environment. In the past, communities, governments, and investors were hesitant to engage in brownfield redevelopment due to its complexity. Moreover, different barriers including lack of capital, lack of a brownfield database, lack of cleanup 
standards, the complexity of rules and regulations, and uncertain conditions are hindering brownfield redevelopment. However, with the emergence of cleanup technologies, demand for urban land, and extensive focus on environmental issues, brownfield redevelopment has emerged as a significant environmental strategy.

Plentiful environmental, social, and economic benefits are attached to brownfield redevelopment [26-31]. After a comprehensive literature review, this study summarized brownfield redevelopment benefits as shown in Figure 1.

- Create employment opportunities

- Increase in taxes

- Increase in property value

- Promote green economy

- Reduce urban sprawl

- Increase competitiveness for cities

- Increase export potential for cleanup technologies
- Reduce pressure on Greenfields

- Reduce pollution

- Improve environment quality

- Promote utilization of renewable resources at brownfield sites

- Improve sustainable development index

- Environmental Justice

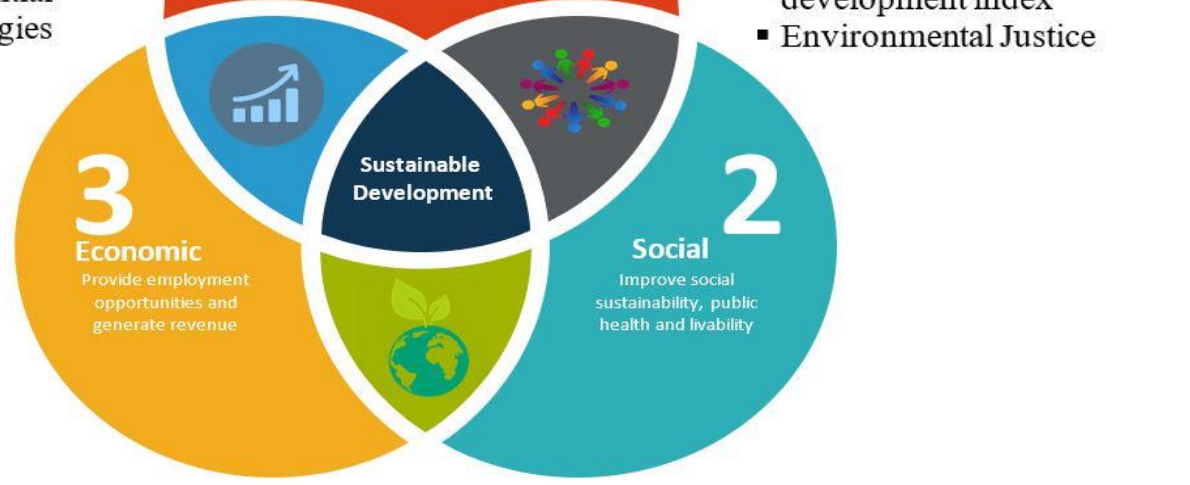

- Renewal of old community

- Develop brownfield into community. commercial market or eco-industrial park

- Improvement in public infrastructure (School, hospital, recreation etc.)

- Improve accessibility

- Reduce crime

Figure 1. Benefits of brownfield redevelopment.

\subsection{Overview of Brownfield Definition}

Generally existing in central locations of the city or along the waterfront and equipped with existing infrastructure, brownfield is environmentally depleted land that requires redevelopment for productive usage and connection to the natural environment [32]. However, transforming brownfield sites as part of a sustainable environmental policy is capturing attention globally, increasing the trend of redeveloping brownfield while keeping the environment preserved. There is a lack of understanding about the definition of brownfield, but also misconceptions about different kinds of brownfield, which is generally due to the following three factors:

The first is the association of multiple words like vacant, contaminated, hazardous, underused, and polluted with a single word, brownfield. For example, Tyman defined brownfield as "Post-industrial sites." Ekman counters that, since 1990, the definition has rapidly advanced to incorporate different kinds of sites along with post-industrial sites [33].

Secondly, the emergence of different words to define the concept of brownfield has increased the number of terms, subdivisions and typologies in play (Table 1).

Third, multiple definitions of brownfield have emerged in different countries (Table 2). 
Table 1. Subdivisions of brownfield.

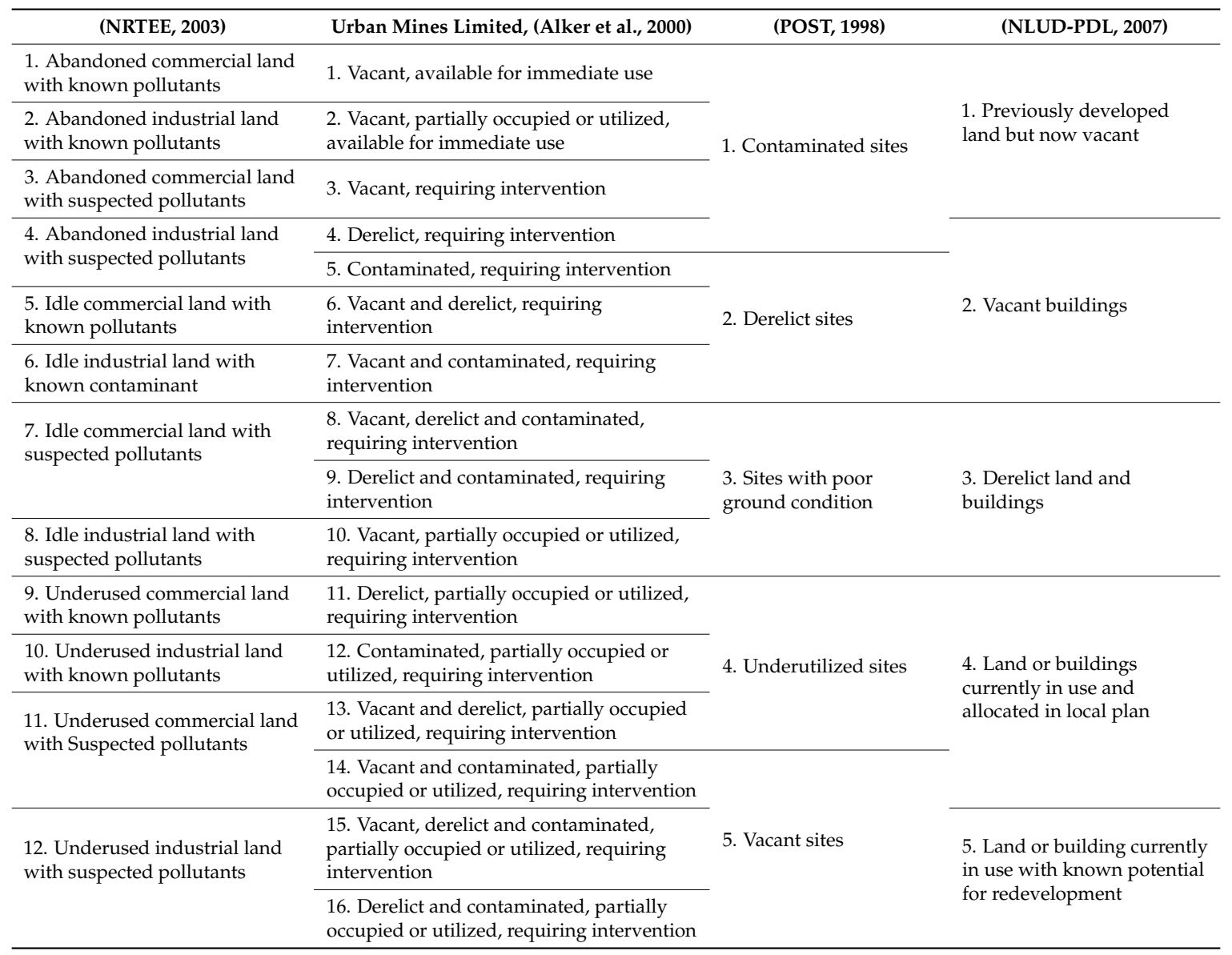

Table 2. Definitions of brownfield from different countries.

\begin{tabular}{|c|c|c|}
\hline Country & Source & Definition \\
\hline USA & USEPA [34] & $\begin{array}{l}\text { "Abandoned, idled, or under-used industrial and commercial facilities where expansion or } \\
\text { redevelopment is complicated by real or perceived environmental contamination." }\end{array}$ \\
\hline Canada & De Sousa [35] & $\begin{array}{l}\text { "Abandoned, idle or underused commercial or industrial sites where previous activities have } \\
\text { caused environmental contamination, but where there is an active potential for } \\
\text { redevelopment." }\end{array}$ \\
\hline \multirow[t]{2}{*}{ Europe } & Ferber et al. [36] & $\begin{array}{l}\text { "Currently derelict or underused sites which have been affected by former uses of the site or } \\
\text { surrounding land; they are mainly located in fully or partly developed urban areas and may } \\
\text { have real or perceived contamination problems thus require intervention to bring them back } \\
\text { to beneficial use." }\end{array}$ \\
\hline & Cabernet [37] & $\begin{array}{l}\text { "A site that has been affected by former uses of the site or surrounding land, is derelict or } \\
\text { underused, mainly in fully or partly developed urban areas, require intervention to bring it } \\
\text { back to beneficial use; and may have real or perceived contamination problems." }\end{array}$ \\
\hline UK & Post [38] & $\begin{array}{l}\text { "Brownfield sites are buildings and land either now vacant, or that could become vacant or } \\
\text { suitable for development, during a relevant [development]plan period." }\end{array}$ \\
\hline France & Darmendrail [39] & $\begin{array}{l}\text { "A space that has been temporarily abandoned following the cessation of activity } \\
\text { (agricultural, protoindustrial, service, processing, military defense, storage or transport) and } \\
\text { that needs to be reclaimed for future use." }\end{array}$ \\
\hline Germany & Freier [40] & $\begin{array}{l}\text { "Abandoned pieces of land, mainly in inner cities, which are often blocked for economic } \\
\text { development due to their ecological and economic risks." }\end{array}$ \\
\hline Australia & Newton [41] & $\begin{array}{l}\text { "A brownfield site is one which has been urbanized or used industrially, subsequently } \\
\text { vacated and available for re-urbanization." }\end{array}$ \\
\hline South Africa & Potts and Cloete [42] & $\begin{array}{l}\text { "A brownfield site is infill land or premises where remedial action is required before } \\
\text { redevelopment. It may also be vacant, derelict or contaminated. No specific land use is } \\
\text { attributed." }\end{array}$ \\
\hline
\end{tabular}


According to De Sousa, different brownfield land characteristics like derelict, post-industrial, and contaminated are synonymous with the term brownfield in the USA and Canada [35]. However, brownfield being perceived as spaces caused by the abandonment of industrial sites not only due to socioeconomic changes, but also due to the poor performance of the industrial sector, somehow got recognition, and researchers more or less agreed [33]. There is much more ambiguity about the definition of brownfield, which gives rise to contradictions geographically and between scholars. Alker et al. pointed out that the lack of a universally accepted brownfield definition has consequences in terms of there being multiple interpretations of the term [10].

One of the major arguments among researchers is about the absence or presence of pollutants on brownfield sites. The degree of pollutants influences the definition of brownfield. Ekman and the U.S. EPA indicated the presence or potential presence of contaminants, hazardous materials, or pollutants, or at least a degree of pollutants [43]. Though a brownfield site may be clean, the potential presence of contaminants makes it brownfield. This idea is also affirmed by POST, which explains that "not all brownfields are pollutants or derelict" [38]. Franz et al. [44] opposed the definition given by Ekman and did not associate contaminants with brownfield.

The abovementioned discrepancies make the term brownfield more ambiguous. However, the existence or non-existence of pollutants is a necessary element for the transformation of these sites; as indicated by several researchers, if no significant pollutants are found, the site value increases, allowing more chances for redevelopment, whereas if pollutants are found, the site value decreases [32].

Public perception about brownfield also varies. Some people perceive it as an opportunity for recreational activities, and some consider it dangerous to human life [10,32]. Based on the work of Alker, Joy, Roberts and Smith [10], Tarawneh [45] and Loures and Vaz [27] developed a brownfield classification in Europe and Middle East as shown in Figures 2 and 3. Considering the discrepancies of brownfield definitions, as mentioned in the above literature, it is necessary to develop a brownfield definition through a consensus of all stakeholders in the Pakistani context.

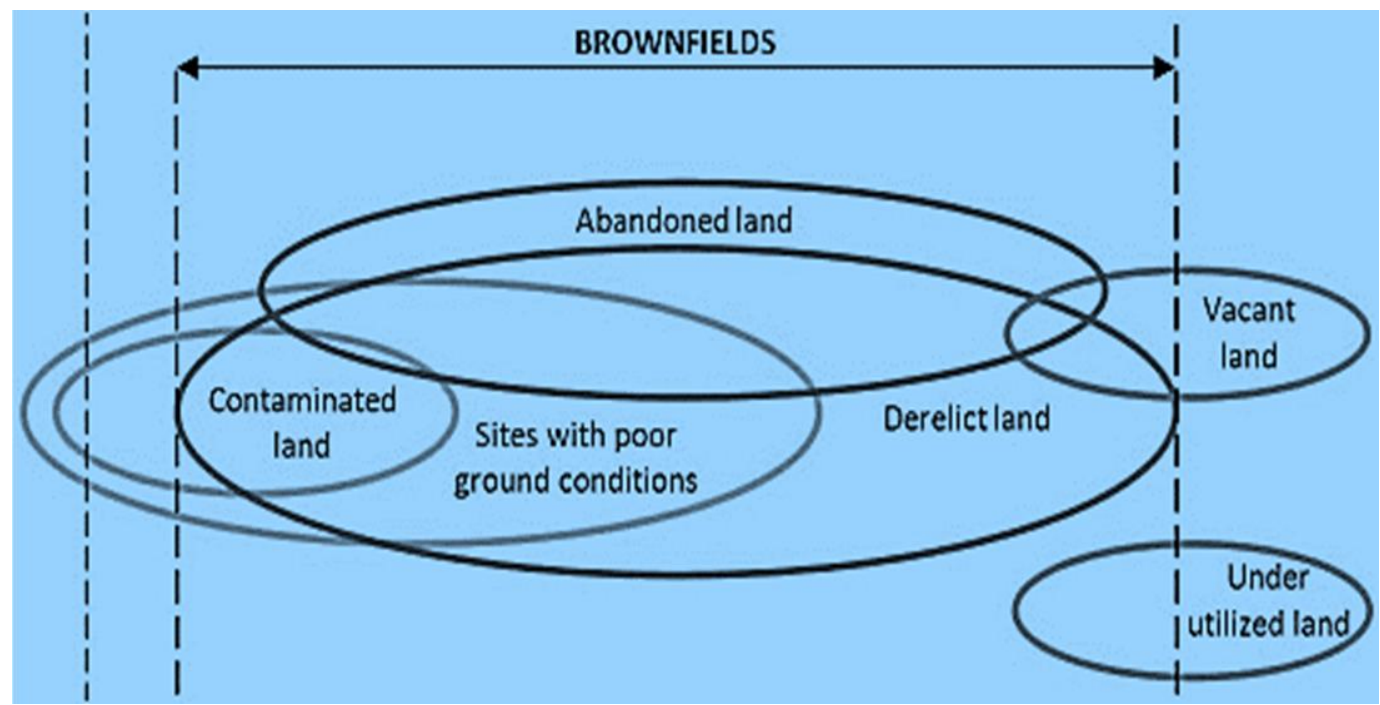

Figure 2. Subdivisions of brownfield [46]. 


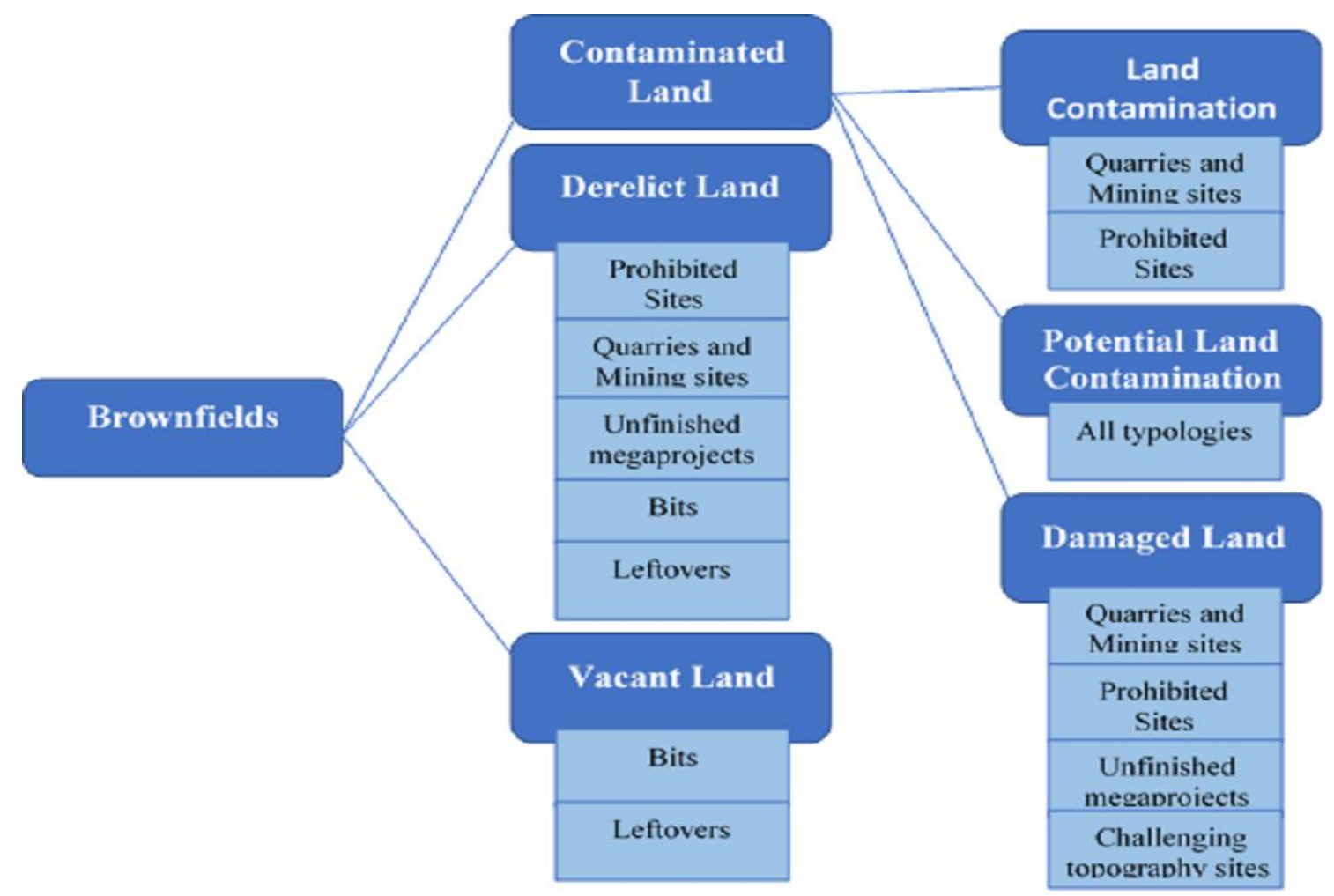

Figure 3. Brownfield classification $[10,45]$.

It is clear from the above discussion and Tables 1 and 2 that the current definitions of brownfield vary among countries (sometimes even within countries) according to the suitability of stakeholders. However, these definitions cannot be adopted in the same form due to the changes in rules and regulations, brownfield characteristics, supply, and demand for brownfield. Therefore, it is necessary to develop a consensus-based brownfield definition and guidelines for developing countries, especially for Pakistan. A consensus-based brownfield definition and guidelines will be helpful for developing urban land use policy and fostering urban sustainability in developing countries, especially in Pakistan.

\subsection{Assessing Brownfield Redevelopment through GRA and TFNs}

GRA has been widely utilized by researchers to make decisions about different alternatives in a specific situation. It has been recommended as a system to identify the factors affecting a system. Moreover, this method is more effective due to its ability to describe a qualitative index with the help of quantitative values while deciding about different alternatives. Therefore, GRA reduces complexity and makes it easy to quantify qualitative indicators. However, judging the fuzzy characteristics of a qualitative index is complicated and not easy to determine. Different engineering and social science researchers resolved this complication by introducing fuzzy theory into the GRA.

This method also gives a solution for the calculation of perceived relative distance between two fuzzy numbers (FNs) to find the single characteristic relational coefficient value $[47,48]$. The product of the determined value of coefficient and weighting coefficient leads us to obtain a grey relational degree for each alternative. The numerical order of grey relational degree helps us to choose an ideal scheme. However, a combination of FNs and GRA still has deficiencies because it utilizes a defuzzification method to calculate the relational coefficient and find a correlation between two numbers by employing the relative distance of two points rather than taking its algorithm [49].

TFNs are commonly used in fuzzy theory due to their ability to describe linguistic variables in studies and the ease of use in operations and size comparison [48]. As fuzzy language can also be present in the evaluation index of brownfield redevelopment, this study utilizes TFNs to collect data on different qualitative evaluation indicators of brownfield redevelopment. Moreover, conversion of 
the fuzzy index into TFNs also helps the study to calculate the grey relational coefficient. Integration of TFNs and grey relational coefficient leads us to obtain a fuzzy relational coefficient through the operation and sorting method of TFNs. By making a comparison of the fuzzy relational coefficient for each scheme, an ideal scheme can be selected that proves the establishment of a comprehensive evaluation framework for brownfield redevelopment.

\section{Methodology}

This section provides a step-by step study approach and explains the development of the questionnaire, data collection, and solution methodology to develop an evaluation index system for BR.

\subsection{Research Methodology}

This study aims to develop a standard definition, guidelines, and evaluation index system for brownfield in developing countries, especially in Pakistan. To achieve the objective, this study first performed a comprehensive literature review for brownfield definition, guidelines, and evaluation index system indicators. Then, the Delphi Method was used to screen out the indicators for the final questionnaire. Finally, stakeholder response was collected through a structured questionnaire. A step-by-step study approach is shown in Figure 4.

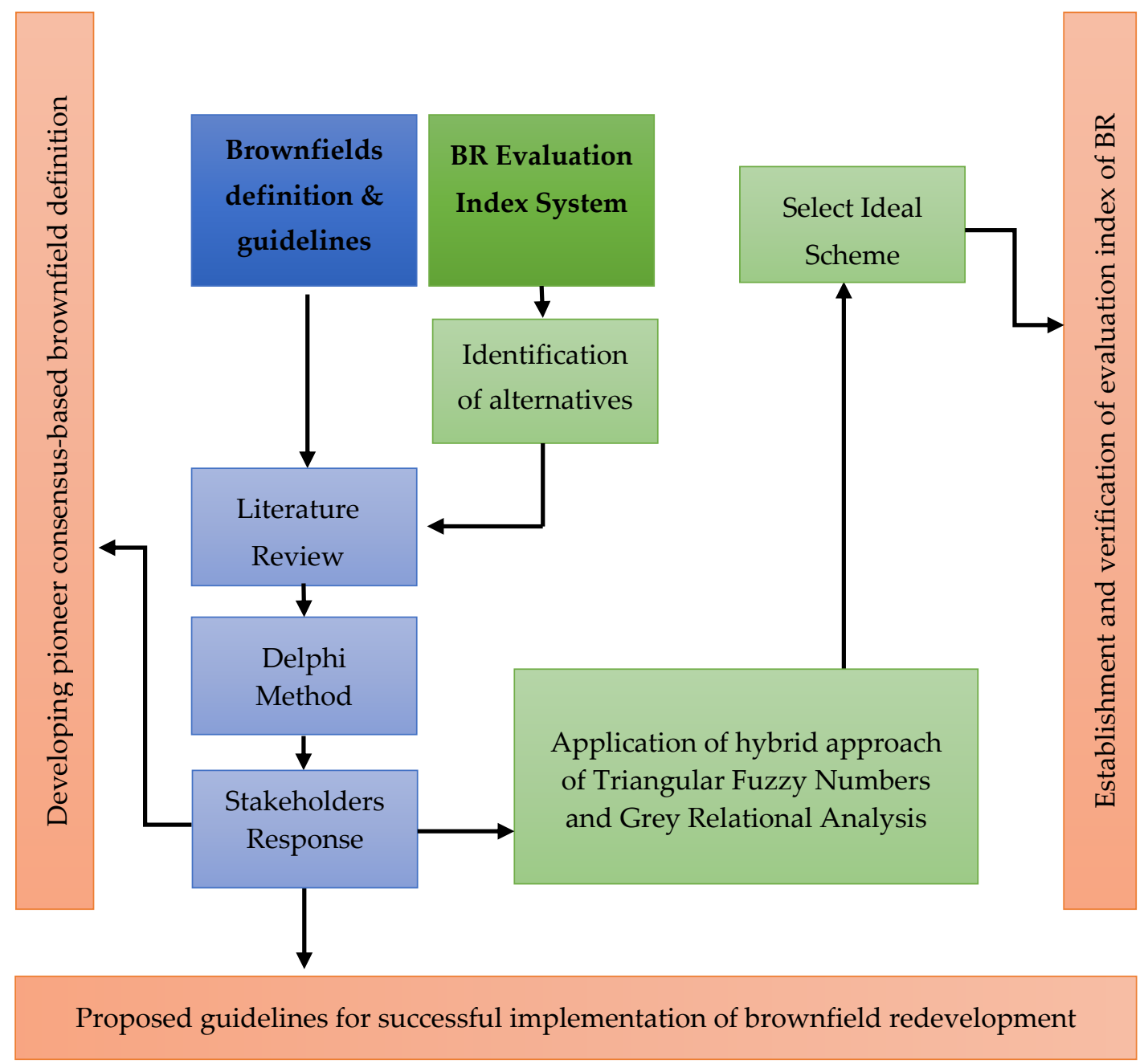

Figure 4. Step-by-step study approach. 
A comprehensive literature review was performed to investigate the concept of brownfield in different contexts. However, a consensus-based universal definition is still lacking, and the brownfield term is understood differently in different countries. In Pakistan, it is an unfamiliar term or correlated with other terms. Therefore, it is necessary to depend on the international literature to develop a consensus-based brownfield definition. Due to the unfamiliarity of the concept, the selection of respondents was a difficult task.

Moreover, the selection of an appropriate sampling technique was also an issue. A combination of three sampling techniques including purposive, judgment, and snowball was considered to collect data from different stakeholders as mentioned above. Judgment sampling technique relies heavily on the researcher's experience in a specific area of research and the snowball sampling technique is a reference-based technique where respondents can identify other respondents to give an appropriate response. Before proceeding to data collection, pilot testing was performed to check respondents' knowledge about brownfield. Some simple questions were asked including (1) Are you familiar with brownfield? and (2) Do you know about the remediation of contaminated land for sustainable development? The respondents were eligible to give response in case of certain scores obtained in pilot testing. Therefore, the purposive sampling technique was chosen based on the subjective judgment of the researcher to get appropriate respondents.

A survey-based questionnaire was developed to get information from relevant stakeholders. The questionnaire was composed of three sections. The first section includes general and demographic information; the second section includes questions related to possible elements of the brownfield definition, and the third section includes different evaluation indicators of BR. Initially different elements of the brownfield definition were explored from the published literature as shown in Tables 1 and $2[10,38,50,51]$, and different evaluation indicators were also identified [23,24,52-58]. Following the Delphi Method, as suggested by different researchers in the management sciences research [59], a group of experts screened a primary set of brownfield definition elements and evaluation indicators to develop the questionnaire.

Finally, a total of 10 brownfield definition elements were screened out, including (1) vacant, (2) abandoned, (3) hazardous, (4) buildings, (5) derelict, (6) underused, (7) pollutant, (8) post-industrial, (9) urban, and (10) idle. Twenty-three indicators were screened (out of 33 initially proposed) to develop a comprehensive evaluation index to evaluate BR. Moreover, different questions regarding the development of brownfield guidelines were also added. These questions included 1) Is there any brownfield database available in the country? and 2) What are the different benefits associated with brownfield? (The key benefits, adopted from previous studies, included infrastructure, recreational, economic, health and safety, and environmental benefits. [27]) 3) Describe the department and authorities responsible for dealing with brownfield issues (an open-ended question). For the last question, respondents had the freedom to give an open response to developing brownfield guidelines and a database, which were included in the proposed guideline section.

All the questionnaires were distributed between July 2016 and December 2016. Master's-level university students were recruited for nominal remuneration to collect data from stakeholders. A total of 500 questionnaires were distributed, and 140 (government institutions $=57$, public and private investors and developers $=33$, local citizens $=38$, NGOs $=12$ ) were returned, a $29 \%$ response rate. The response rate was too low due to the unfamiliarity of the term brownfield in Pakistan. This also underscores the significance and generalizability of this research. 


\subsection{Solution Methodology for the Evaluation Index System}

\subsubsection{The Basic Definition of TFNs}

The domain of $\mathrm{V}$ is denoted by a real number in the closed interval $[0,1]$, where $v V, \mu_{A}(V)$, can be represented as the membership function

$$
\mu_{A}: V \rightarrow[0.1], v \mid \rightarrow \mu_{A}(v)
$$

Let a fuzzy number $\mathrm{A}$ in the subset of a real number with membership function $\mu_{N}: V \rightarrow[0,1]$ be described in this form:

$$
\mu_{A}(x)=\left\{\begin{array}{l}
\frac{1}{k-x} x-\frac{l}{k-l}, x \in[l, k] \\
\frac{1}{k-v} x-\frac{v}{k-v}, x \in[k, v] \\
0, x \in(-\infty, l] \cup[v,+\infty)
\end{array} .\right.
$$

Let a triplet $(l, k, v)$ be known as TFNs. The fuzzy number can be transformed into TFNs, where $l$ is indicated as the lower value, $v$ shows the upper value, and $k$ is the mid-value in which the membership value function of TFN is equal to 1 . Therefore, in terms of TFN, A can be described as, $A(l, k, v)$. In light of the above description, the fuzzy number can be expressed as $K 1=(l 1, k 1, v 1), K 2=(l 2, k 2, v 2)$ and the different operational rule of numbers $K 1$ and $K 2$ can be expressed as follows:

(1) Summation Operation $K 1+K 2=(l 1+l 2, k 1+k 2, v 1+v 2)$

(2) Product Operation: $K 1 \otimes K 2 \approx(l 1 l 2, k 1 k 2, v 1 v 2)$

(3) Reciprocal Operation: $\frac{1}{A} \approx\left(\frac{1}{v}, \frac{1}{k}, \frac{1}{l}\right)$

Other algorithms can be extended based on earlier algorithms.

Based on the above algorithms, other algorithms can be deduced.

\subsubsection{Sorting of TFNs}

To sort fuzzy numbers, Lee and Li recommended using average and standard deviation. In the case of high average and low standard deviation of a fuzzy number, its rank is considered high [60]. The distribution of the ratio of TFNs can be described in the form of $\widetilde{r}_{i}(d, e, f), i=1,2,3, \ldots, n$. To calculate the average $\bar{x}\left(\widetilde{r}_{i}\right)$ and standard deviation $\sigma\left(\widetilde{r}_{i}\right)$; the following formula can be used:

$$
\begin{gathered}
\bar{x}\left(\widetilde{r}_{i}\right)=\frac{1}{4}(d+2 e+f) \\
\sigma\left(\widetilde{r}_{i}\right)=\frac{1}{80}\left(3 d^{2}+4 e^{2}+3 f^{2}-4 d e-2 d f-4 e f\right)
\end{gathered}
$$

For size comparison of fuzzy numbers, the rule can be described as follows:

$$
\begin{gathered}
\text { if } \bar{x}\left(\widetilde{r}_{i}\right)>\bar{x}\left(\widetilde{r}_{j}\right) \text { then } \widetilde{r}_{i}>\widetilde{r}_{j}, \\
\text { if } \bar{x}\left(\widetilde{r}_{i}\right)=\bar{x}\left(\widetilde{r}_{j}\right), \sigma\left(\widetilde{r}_{i}\right)>\sigma\left(\widetilde{r}_{j}\right) \text { then } \widetilde{r}_{i}>\widetilde{r}_{j} .
\end{gathered}
$$

\subsubsection{Combining GRA and TFN}

Following the principle of grey system theory as founded by [61], the comparative sequence, $S_{i}(j)=\left\{S_{i}(1), S_{i}(2), \ldots, S_{i}(n)\right\}$, here $i(i=1,2, \ldots n)$ indicates the number of different alternatives and $j(j=1,2, \ldots n)$ points out the numbers in each alternative. $S_{i}(j)$ presents the index of $j$ numbers in an alternative $i$; however, for the description of the reference sequence, $S_{0}(j)=\left\{C_{0}(1), C_{0}(2), \ldots C_{0}(n)\right\}$, where $\left(C_{0}(j), j=1,2, \ldots n\right)$ indicates the index of no. $j$ of the reference sequence. Based on the 
comparative sequence and reference sequence, the coefficient of relational degree can be obtained as shown in Equation (4):

$$
\xi(j)=\frac{\min _{i} \min _{j}\left|S_{0}(j)-S_{i}(j)\right|+\rho \max _{i} \max _{j}\left|S_{0}(j)-S_{i}(j)\right|}{\left|S_{0}(j)-S_{i}(j)\right|+\rho \max _{i} \max _{j}\left|S_{0}(j)-S_{i}(j)\right|} .
$$

Although the comparative sequence index $S_{i}(j)$ and a reference sequence index $S_{0}(j)$ are useful to an extent, it is still complicated to integrate fuzzy numbers into GRA. To solve the problem of fuzziness in the integration of grey relational coefficient into a fuzzy number, Rui introduced a way to transform the fuzziness in index into a certain value to obtain the required results by using Equation (4) [62].

Although this is an easy approach, the results are not consistent due to the existence of fuzziness in an index. The fuzzy grey relational coefficient method provides the solution to the problem of fuzziness by combining fuzzy theory with grey relational theory. Therefore, after combing fuzzy and grey relational theory, the comparative sequence is described as $S_{i}\left\{A_{i}\left(l_{j}, k_{j}, v_{j}\right)\right\}$ and TFN is described as $A_{i}\left(l_{j}, k_{j}, v_{j}\right)$, where index $j$ represents an alternative $i$ in the reference sequence ${ }_{0}$. By using Equation (5), the fuzzy correlation coefficient in the index $A_{i}\left(l_{j}, k_{j}, v_{j}\right)$ can be obtained as follows:

$$
\xi_{i}(j)=\frac{\min _{i} \min _{j}\left|A_{o}\left(l_{j}, k_{j}, v_{j}\right)-A_{i}\left(l_{j}, k_{j}, v_{j}\right)\right|+\rho \max _{i} \max _{j}\left|A_{o}\left(l_{j}, k_{j}, v_{j}\right)-A_{i}\left(l_{j}, k_{j}, v_{j}\right)\right|}{\left|A_{o}\left(l_{j}, k_{j}, v_{j}\right)-A_{i}\left(l_{j}, k_{j}, v_{j}\right)\right|+\rho \max _{i} \max _{j}\left|A_{o}\left(l_{j}, k_{j}, v_{j}\right)-A_{i}\left(l_{j}, k_{j}, v_{j}\right)\right|} .
$$

With the help of Equation (5), operation rule and ranking method solve the problem of maximum, minimum and arithmetic operation of TFN. The resolution ratio can be described here as $\rho \in(0,+\infty)$. If the resolution ration is smaller, the resolution capability will be greater (general $\rho \in(0,1)$ and more general $\rho=0.5$ ).

\subsubsection{Establishment of an Index System to Evaluate BR}

GRA solves the problem of relative metrics between factors affecting a system. This analysis is based on a relatively objective method to evaluate the weight of an index. Moreover, this methodology requires little information and a low data size for ideal alternative selection.

Moreover, another benefit to making this kind of analysis suitable for ideal alternative selection is the requirement of small data size and little information. Rui and Jiatai [63] established a hierarchal evaluation model using GRA and calculated the relational coefficient after transformation of the fuzzy index into a certain value using Equation (4).

This study follows different steps to establish an index system based on grey relational theory and TFNs:

In the first stage, three different alternatives were suggested for brownfield redevelopment including the housing society, an eco-industrial park, and a commercial market.

In the second stage, a comprehensive literature review was performed to establish an index system for BR. Through the Delphi Method, different indicators of the index were evaluated by different experts to develop a final questionnaire.

Data were obtained from different stakeholders involved in the brownfield redevelopment process.

After obtaining responses from different stakeholders, we collected data through a fuzzy index and transformed them into TFNs with the help of an index value sequence that further leads to obtaining comparative sequence $S_{i}(j)=\left\{A_{i}\left(l_{j}, k_{j}, v_{j}\right) \mid j=1,2, \ldots, n\right\}$.

Then, the principle of comparability was utilized to calculate the value of the reference sequence using $S_{0}(j)=\left\{N_{0}\left(l_{j}, n_{j}, v_{j}\right) \mid j=1,2, \ldots, n\right\}$. The next step is to make the index non-dimensional. 
Due to the difference in indicators, comparing every sub-index is difficult. Therefore, it is necessary to make the index dimensionless with the help of Equation (6):

$$
\begin{gathered}
X_{i}(j)=X_{i}\left\{x_{i}\left(c_{j}, f_{j}, t_{j}\right)\right\}=\frac{S_{i}(j)}{S_{j}}=\frac{A_{i}\left(l_{j}, k_{j}, v_{j}\right)}{S_{j}} \\
S_{j}=\frac{1}{n+1} \sum_{i=1}^{n} A_{i}\left(l_{j}, k_{j}, v_{j}\right)(i=1,2, \ldots n, j=1,2, \ldots n) .
\end{gathered}
$$

This step brings the non-dimensional reference sequence and comparative sequence together to calculate the grey correlation coefficient having TFNs.

Finally, this stage leads to decision-making about different alternatives for BR. First, the weights $\omega_{j}$ of the developed index system for brownfield redevelopment were obtained by using an Analytical Hierarchy Process (AHP). Then Equation (6) was used to calculate the fuzzy correlation coefficient. Finally, the overall fuzzy correlation degree of the abovementioned alternatives was obtained with the help of Equation (7):

$$
\gamma_{i}=\sum_{j=1}^{n} \omega_{j} \varepsilon_{i}\left(c_{j}, f_{j}, t_{j}\right)(i=1,2, \ldots n)
$$

\section{Results and Discussion}

This section describes the findings on the development of a standard brownfield definition, guidelines, and an evaluation index system for BR.

\subsection{Developing a Brownfield Definition}

Respondents were asked to select the most important element that should be part of the definition of brownfield in Pakistan. Figure 2 shows the proportion of the importance of every element as follows:

Vacant $(26 \%)$, environmental pollutant $(22 \%)$, and urban area $(18 \%)$ scored the highest, while derelict (12\%) scored slightly lower; underuse, post-industrial, abandoned, buildings, idle, and hazardous scored lower.

Different brownfield definition elements defined by previous research $[10,38,50,51]$ were used as the basis for developing a consensus-based definition in the Pakistani context. In developing a pioneer definition, it is important to consider all relevant aspects. Although there are already well-accepted terms associated with brownfield land like empty, derelict, and polluted, these can create confusion and thus are a constraint on the development of a pioneer brownfield definition in this country. After considering the international literature, expert opinion, and stakeholders' data, the pioneer consensus-based brownfield definition for Pakistani context can be proposed as follows:

"Brownfield land is infilled sites that generally exist in urban centers, where remedial activities are required before development; it may be:

(1) environmentally polluting (with a potential for hazardous substances due to former industrial applications),

(2) vacant (currently not in use and available for remedial action), or

(3) derelict (land that is damaged by former industrial activities and cannot potentially contribute to sustainability without being remediated"

Stakeholders' responses regarding different elements of the brownfield definition are shown in Figure 5. Results show that environmental pollutants contribute more to the standard definition of brownfield in Pakistan in comparison with derelict, idle, or hazardous, which proves the need for a brownfield definition in the developing country context because idle and derelict are two of the most consistent elements of previous brownfield definitions in developed countries [34-41]. 


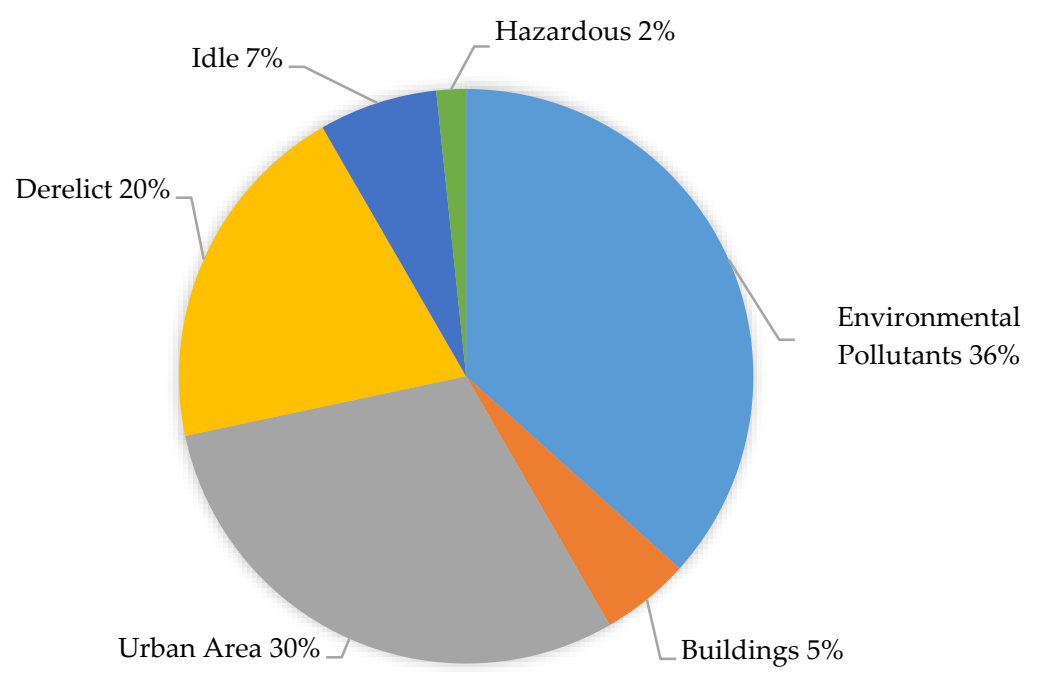

Figure 5. Elements of brownfield definition in Pakistan.

\subsection{Proposed Guidelines}

Brownfield issues are in their infancy in Pakistan. Therefore, it is important to follow different guidelines from international literature and stakeholders. The proposed guidelines are given below:

1. As this study developed a consensus-based brownfield definition in the Pakistani context, the proposed definition needs wide acceptance from relevant local, provincial, and federal authorities. Moreover, initiatives should be taken to include the established definition in the national legislation to promote its standard use across the country [64].

2. An established evaluation index should be incorporated to evaluate BR. Due to the complex nature of the BR process, this index can be used to evaluate different alternatives regarding the redevelopment of brownfield. This indexing system integrated ecological, social, political, economic, recreational, accessibility, and brownfield site-based indicators. Therefore, this index system needs to be evaluated for different kinds of brownfield, e.g., urban, railway, mining, and coastal.

3. Most of the stakeholders indicated of the need for a brownfield database. Therefore, this research recommends developing a brownfield database to foster brownfield redevelopment in Pakistan. However, there should be special consideration of different aspects regarding a brownfield database, which include: the location of brownfield, connected public infrastructure, previous use, nature of hazardous substances or pollutants at brownfield sites, the proposed plan, the estimated cost of remediation, and geotechnical conditions. The details about the need for a brownfield database are shown in Figure 6.

4. Regarding the question of the benefits associated with brownfield redevelopment, the majority of stakeholders mentioned environmental benefits, as brownfield redevelopment decreases pollution and improves the environment. Therefore, considering the alarming situation of brownfield in Pakistan, brownfield redevelopment should be implemented to get rid of environmental pollution in city centers. The stakeholders' responses regarding the benefits of brownfield redevelopment are shown in Figure 7.

5. In response to the question about responsible authorities regarding brownfield redevelopment, most of the stakeholders considered the Environmental Protection Agency and local government as responsible authorities to promote brownfield redevelopment in Pakistan. These institutes also need cooperation from other supportive institutes including urban planning institutes, planning and development departments, sustainable land management programs, and land record authorities. Stakeholders' responses regarding the responsible authorities to deal with brownfield issues are shown in Figure 8. 
6. Local and federal authorities should collaborate to develop policy on the successful implementation of brownfield redevelopment. In the case of cities, local municipalities should create sub-units to control brownfield issues effectively [65]. Communities have the most significant role in the brownfield redevelopment process as they are the ultimate users. Awareness-based seminars and campaigns should be organized to foster public participation in the brownfield redevelopment process [66].

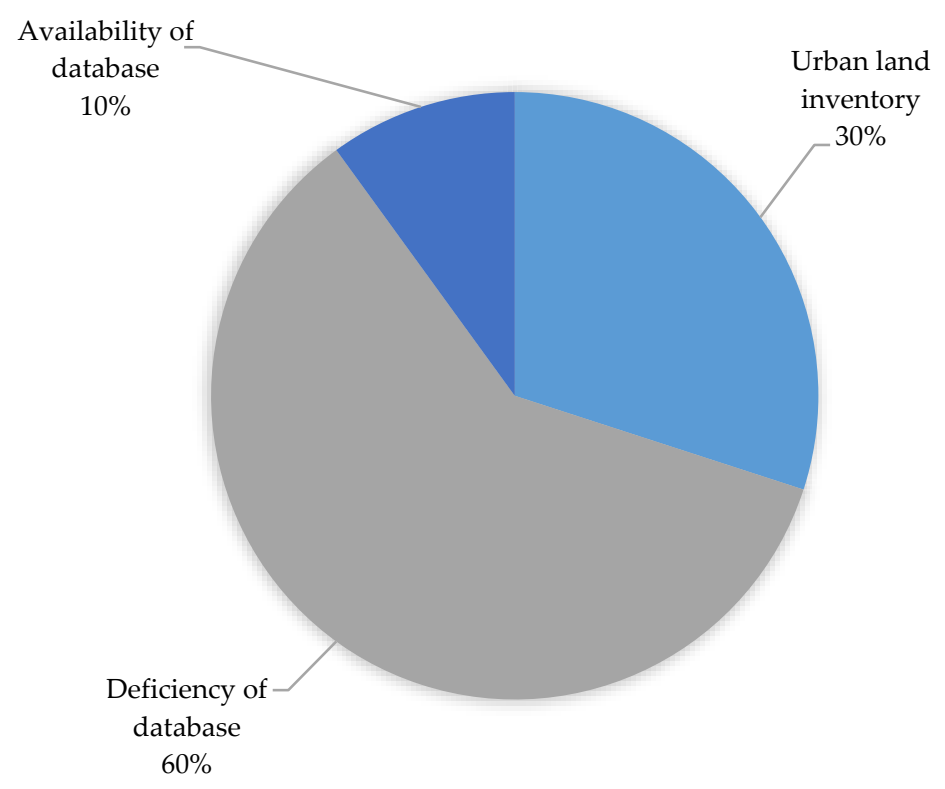

Figure 6. The need for a brownfield database.

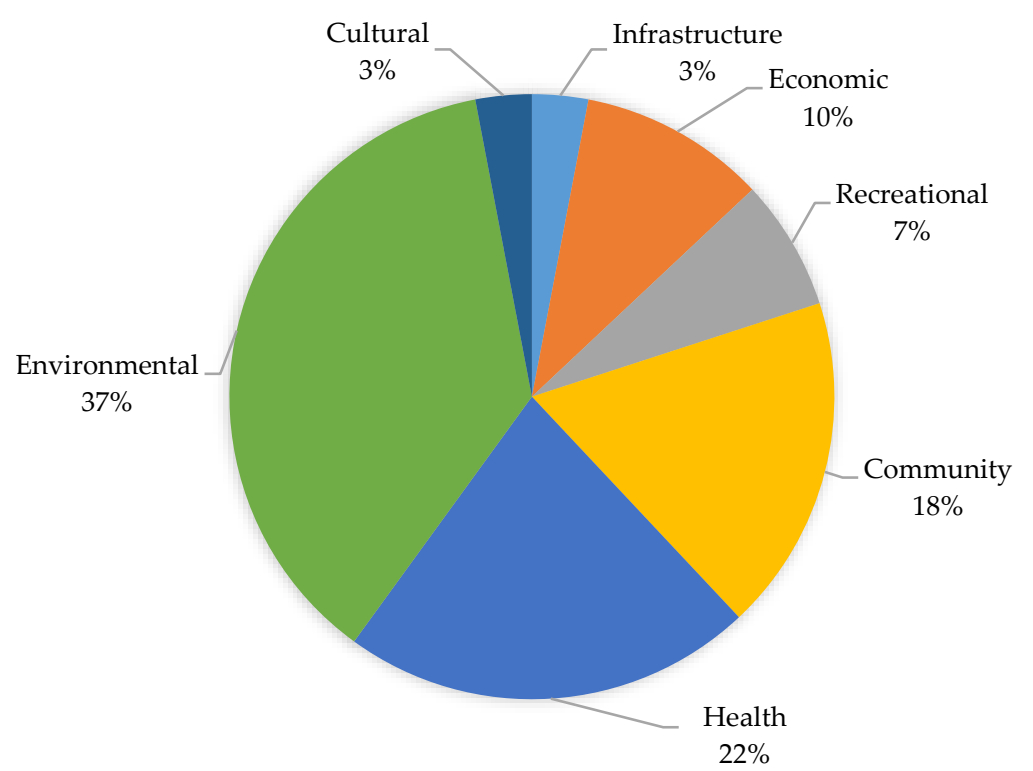

Figure 7. Key benefits associated with brownfield. 


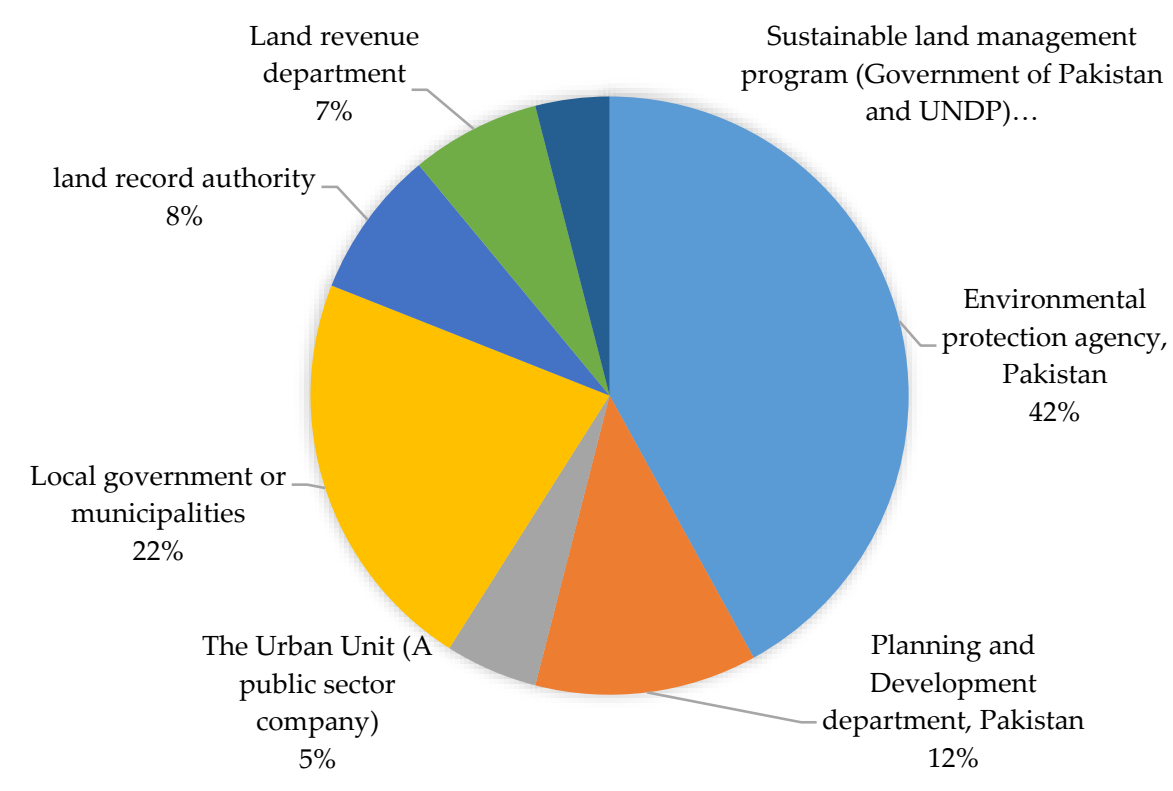

Figure 8. Responsible departments and authorities to deal with brownfield issues.

\subsection{Application of Established Brownfield Redevelopment Evaluation Index through an Illustrative Example}

Suppose that a government is interested in redeveloping a brownfield site and has to judge three different alternatives according to the suitability of the land. This process starts with an overview of a brownfield site and develops different alternatives/schemes. A comprehensive index system of brownfield redevelopment evaluation considering three different alternatives was applied. Although there may be many potential alternatives to redeveloping the brownfield, considering the shortage of urban land for housing, commercial activities, and sustainability initiatives in the Pakistan land market situation, the three proposed alternatives are:

A1: Building a housing society;

A2: Establishing an eco-industrial park;

A3: Building a commercial market.

First, the proposed index system (with sub-indexes) was presented. Then, different stakeholders were requested to evaluate the three abovementioned alternatives with the fuzzy linguistic terms (SD, DA, NE, AG, and SA), as shown in Table 3. For the application of the proposed evaluation index system, the response in the form of fuzzy linguistics terms was transferred to corresponding TFNs. An example of the response from an expert is shown in Table 4.

Table 3. Fuzzy index and corresponding TFNs.

\begin{tabular}{ccc}
\hline Linguistic Terms & Abbreviation & TFNs \\
\hline Strongly Disagree & SD & $(0,1,2)$ \\
Disagree & DA & $(2,3,4)$ \\
Neither Disagree nor Disagree/Neutral & NE & $(4,5,6)$ \\
Agree & AG & $(6,7,8)$ \\
Strongly Agree & SA & $(8,9,10)$ \\
\hline
\end{tabular}


Table 4. Comprehensive evaluation index system.

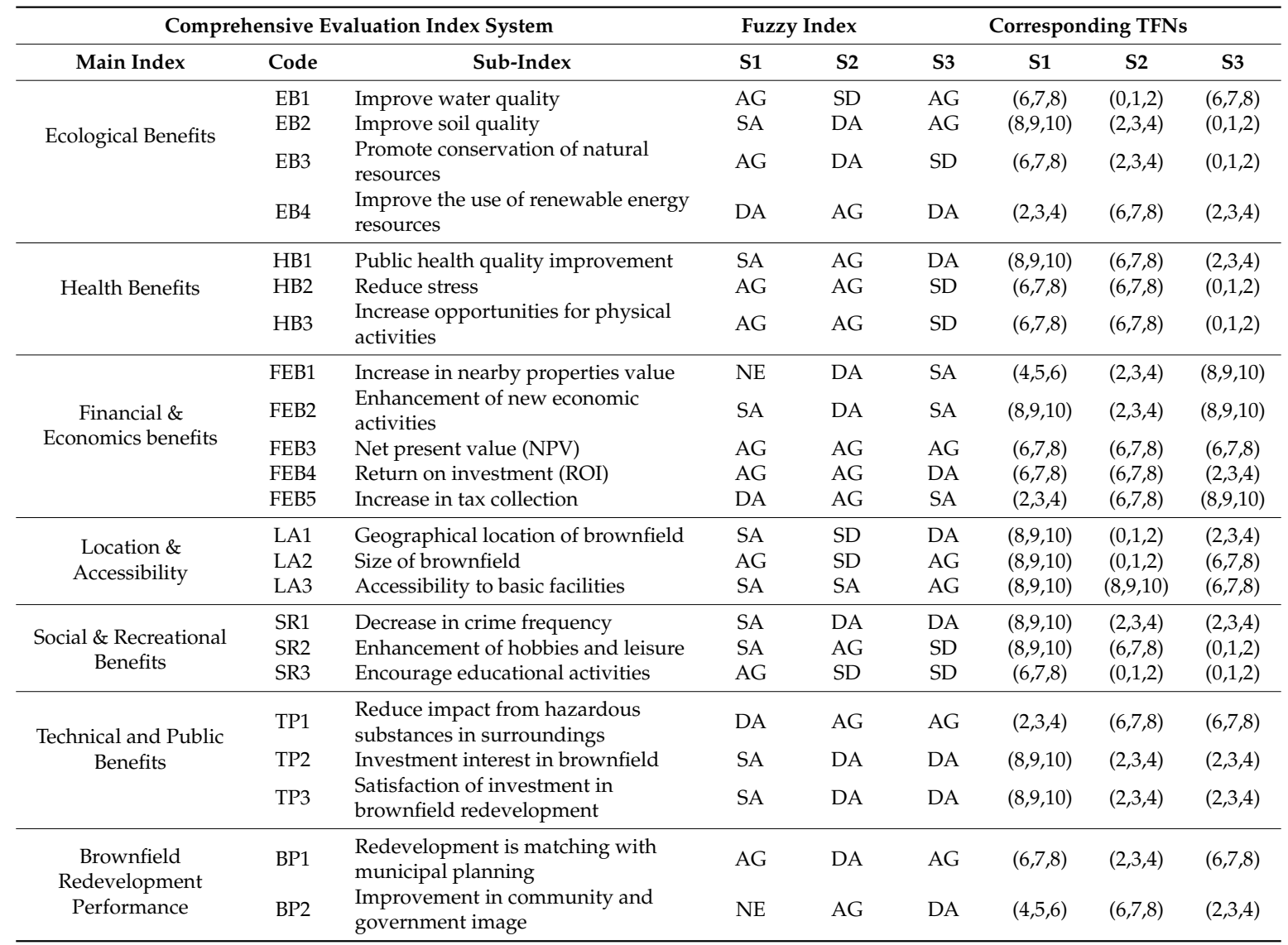

The transformation of the fuzzy index into TFNs further leads to obtaining a comparative sequence. After that, we chose a reference sequence and implemented the dimensionless method with regards to both the comparative sequence and the reference sequence. Table 5 shows the application of the dimensionless method and the final values of the reference sequence. Then, we inserted all the values of the reference sequence and comparative sequence obtained through a dimensionless method in Equation (6). This led to calculating the fuzzy grey relational coefficient for each scheme and values are shown in Table 5.

Now, following the guidelines of $\mathrm{Mu}$ and Zhang [62], weights were calculated through the approach of the hierarchal house of quality: $\left\{\omega_{i}, i=1,2,3, \ldots, 23\right\}=\{0.134,0.023,0.062,0.062,0.062$, $0.089,0.216,0.145,0.356,0.126,0.098,0.785,0.123,0.145,0.456,0.897,0.156,0.435,0.345,0.989,0.178$, $0.062,0.793\}$.

Now, we insert the fuzzy grey relational coefficients and index weights into Equation (7) to calculate the overall fuzzy relational degree. It can be calculated as follows:

$$
\begin{aligned}
& \gamma_{1}=\sum_{i=1}^{23} \omega_{i} \varepsilon_{1}\left(c_{i}, k_{i}, v_{i}\right)=(0.268,0.889,2.775) \\
& \gamma_{2}=\sum_{i=1}^{23} \omega_{i} \varepsilon_{2}\left(c_{i}, k_{i}, v_{i}\right)=(0.221,0.772,2.014) \\
& \gamma_{3}=\sum_{i=1}^{23} \omega_{i} \varepsilon_{3}\left(c_{i}, k_{i}, v_{i}\right)=(0.224,0.672,2.489) .
\end{aligned}
$$


Table 5. Dimensionless values and fuzzy grey relational coefficient.

\begin{tabular}{|c|c|c|c|c|c|c|c|c|}
\hline \multirow{2}{*}{ Code } & \multirow{2}{*}{$\begin{array}{c}\begin{array}{c}\text { Reference } \\
\text { Sequence }\end{array} \\
S_{0}\end{array}$} & \multicolumn{4}{|c|}{ Dimensionless Values } & \multicolumn{3}{|c|}{ Fuzzy Grey Relational Coefficients } \\
\hline & & $S_{0}$ & S1 & S2 & S3 & S1 & S2 & S3 \\
\hline EB1 & $(8,9,10)$ & $(0.85,1.07,1.39)$ & $(0.66,0.75,1.11)$ & $(0.66,0.75,1.11)$ & $(0.66,0.75,1.11)$ & $(0.42,1.45,2.34)$ & $(0.42,1.45,2.34)$ & $(0.42,1.45,2.34)$ \\
\hline EB2 & $(8,9,10)$ & $(0.00,1.17,1.42)$ & $(0.44,0.55,0.77)$ & $(0.84,0.66,2.5)$ & $(0.44,0.55,0.77)$ & $(0.28,0.68,0.38)$ & $(1.59,0.42,0.89)$ & $(0.24,0.84,2.87)$ \\
\hline EB3 & $(6,7,8)$ & $(0.00,0.65,2.63)$ & $(0.72,1.55,5.67)$ & $(0.44,0.55,0.77)$ & $(0.72,1.55,5.26)$ & $(0.27,1.00,0.50)$ & $(0.28,1.48,0.23)$ & $(0.23,1.00,0.50)$ \\
\hline EB4 & $(6,7,8)$ & $(0.00,0.58,1.37)$ & $(0.84,0.66,2.52)$ & $(0.72,1.55,5.76)$ & $(0.84,0.66,2.52)$ & $(0.25,0.66,2.83)$ & $(0.22,0.99,3.99)$ & $(0.28,0.93,3.23)$ \\
\hline HB1 & $(8,9,10)$ & $(0.85,1.07,1.31)$ & $(0.00,0.66,2.52)$ & $(0.84,0.66,2.52)$ & $(0.00,0.66,2.52)$ & $(0.26,0.60,1.47)$ & $(0.23,1.00, .505)$ & $(0.21,0.61,2.30)$ \\
\hline HB2 & $(6,7,8)$ & $(0.91,1.15,1.37)$ & $(0.48,0.77,0.98)$ & $(0.00,0.66,2.52)$ & $(0.48,0.77,0.98)$ & $(0.23,1.00,0.50)$ & $(0.23,0.46,2.43)$ & $(0.09,0.23,1.17)$ \\
\hline HB3 & $(8,9,10)$ & $(0.72,1.67,2.52)$ & $(0.44,0.55,0.77)$ & $(0.44,0.55,0.77)$ & $(0.44,0.55,0.77)$ & $(0.27,0.33,2.32)$ & $(0.23,1.00, .505)$ & $(0.23,1.00,0.50)$ \\
\hline FEB1 & $(4,5,6)$ & $(0.00,1.17,1.46)$ & $(0.57,2.45,1.23)$ & $(0.48,0.77,0.98)$ & $(0.57,2.45,1.23)$ & $(1.59,0.42,0.89)$ & $(0.28,1.48,0.23)$ & $(0.22,0.67,1.79)$ \\
\hline FEB2 & $(8,9,10)$ & $(0.72,1.66,2.52)$ & $(0.44,0.55,0.77)$ & $(0.44,0.55,0.77)$ & $(0.44,0.55,0.77)$ & $(0.24,0.84,2.87)$ & $(0.20,0.78,3.12)$ & $(0.26,0.60,1.47)$ \\
\hline FEB3 & $(0,1,2)$ & $(0.85,1.07,1.32)$ & $(0.66,0.75,1.11)$ & $(0.57,2.45,1.23)$ & $(0.66,0.75,1.11)$ & $(0.23,1.00,0.50)$ & $(0.27,0.59,2.89)$ & $(0.23,1.00,0.50)$ \\
\hline FEB4 & $(6,7,8)$ & $(0.00,0.65,2.64)$ & $(0.46,0.74,0.98)$ & $(0.44,0.55,0.77)$ & $(0.46,0.74,0.98)$ & $(0.21,0.82,2.71)$ & $(0.65,0.79,3.61)$ & $(0.28,0.93,3.23)$ \\
\hline FEB5 & $(2,3,4)$ & $(0.85,1.07,1.39)$ & $(1.08,1.38,1.14)$ & $(0.66,0.75,1.11)$ & $(1.08,1.38,1.14)$ & $(0.76,0.92,0.98)$ & $(0.23,1.00, .505)$ & $(0.22,0.99,3.99)$ \\
\hline LA1 & $(4,5,6)$ & $(0.00,1.17,1.49)$ & $(1.34,0.88,1.11)$ & $(0.46,0.74,0.98)$ & $(1.34,0.88,1.11)$ & $(0.28,0.27,0.27)$ & $(0.22,0.19,5.23)$ & $(0.09,0.23,1.17)$ \\
\hline LA2 & $(6,7,8)$ & $(0.00,0.58,1.37)$ & $(0.44,0.55,0.77)$ & $(1.08,1.38,1.14)$ & $(0.44,0.55,0.77)$ & $(0.23,1.00,0.50)$ & $(0.27,0.92,1.62)$ & $(0.21,0.61,2.30)$ \\
\hline LA3 & $(8,9,10)$ & $(0.91,1.15,1.37)$ & $(0.84,0.66,2.51)$ & $(1.34,0.88,1.11)$ & $(0.84,0.66,2.52)$ & $(0.28,1.48,0.23)$ & $(0.22,0.99,3.99)$ & $(0.28,1.48,0.23)$ \\
\hline SR1 & $(6,7,8)$ & $(0.00,1.17,1.46)$ & $(0.48,0.77,0.98)$ & $(0.48,0.77,0.98)$ & $(0.48,0.77,0.98)$ & $(0.29,0.49,2.09)$ & $(0.24,0.40,2.93)$ & $(0.23,1.00, .505)$ \\
\hline SR2 & $(8,9,10)$ & $(0.95,0.96,0.97)$ & $(0.57,2.45,1.23)$ & $(0.57,2.45,1.23)$ & $(0.57,2.45,1.23)$ & $(0.22,0.99,3.99)$ & $(0.28,0.93,3.23)$ & $(0.26,0.60,1.42)$ \\
\hline SR3 & $(6,7,8)$ & $(0.86,1.09,1.38)$ & $(0.66,0.75,1.11)$ & $(0.66,0.75,1.11)$ & $(0.66,0.75,1.11)$ & $(0.23,1.00,0.50)$ & $(1.59,0.42,0.89)$ & $(0.28,1.48,0.23)$ \\
\hline TP1 & $(4,5,6)$ & $(0.00,0.65,2.68)$ & $(1.08,1.38,1.14)$ & $(1.08,1.38,1.14)$ & $(1.08,1.38,1.14)$ & $(0.22,0.99,3.99)$ & $(0.21,0.61,2.30)$ & $(0.26,0.33,2.32)$ \\
\hline TP2 & $(8,9,10)$ & $(0.91,1.15,1.37)$ & $(0.72,1.55,5.36)$ & $(0.72,1.55,5.27)$ & $(0.72,1.55,5.23)$ & $(0.28,1.48,0.23)$ & $(0.23,1.00,0.55)$ & $(0.09,0.23,1.17)$ \\
\hline TP3 & $(6,7,8)$, & $(0.72,1.63,2.50)$ & $(0.00,0.66,2.52)$ & $(0.00,0.66,2.52)$ & $(0.00,0.66,2.52)$ & $(0.26,0.60,1.42)$ & $(0.22,0.67,1.79)$ & $(0.24,0.84,2.87)$ \\
\hline BP1 & $(8,9,10)$ & $(0.85,1.07,1.39)$ & $(0.84,0.66,2.53)$ & $(0.84,0.66,2.52)$ & $(0.84,0.66,2.52)$ & $(0.27,0.79,3.72)$ & $(0.28,1.48,0.23)$ & $(0.28,0.68, .387)$ \\
\hline BP2 & $(8,9,10)$ & $(0.00,1.17,1.46)$ & $(0.57,2.45,1.23)$ & $(0.57,2.45,1.23)$ & $(0.57,2.45,1.23)$ & $(0.28,0.45,1.77)$ & $(159,0.42,0.89)$ & $(0.23,1.00,0.50)$ \\
\hline
\end{tabular}

Using the sorting method of the TFN sequence, the final alternative can be chosen as follows:

$$
\gamma_{1}>\gamma_{3}>\gamma_{2}
$$

The final results show that Alternative 1 (A1) can be chosen as the best one in comparison to the other two alternatives. Therefore, developing a housing society is the best solution for brownfield redevelopment in comparison with the eco-industrial park and commercial market.

\section{Conclusions}

Urban sustainable development has emerged as an important planning tool. Brownfield redevelopment, as a concrete application of sustainable development, is getting attention from academia, industrialists, urban planners, and environmental protection agencies. Considering the soil pollution and the necessity of land for development projects, redeveloping brownfield can foster sustainable development. BR is considered a successful urban land use strategy in developed countries and special attention has been given to brownfield issues in last decade. However, brownfield issues are still in their infancy in developing countries, especially in Pakistan. Therefore, this research aims to develop a standard brownfield definition and an evaluation index for brownfield redevelopment in Pakistan. Based on the findings of this study, the following conclusions can be drawn: First, the established brownfield definition considered environmental pollutants, vacant, and derelict as the most significant elements. Second, different guidelines have been proposed to deal with brownfield issues, including 1) Established brownfield definition should be given wide acceptance by all stakeholders; 2) established evaluation index system should be formally utilized to evaluate different kinds of brownfield; 3 ) brownfield database should be founded; 4) due to the multiple environmental, economic, and social benefits, BR should be considered a sustainable land use policy; 5) local, provincial, and federal authorities should collaborate with each other for successful implementation of BR. Finally, the established evaluation index system was validated with a hypothetical example.

Generally, the prevailing issue during brownfield redevelopment is to complete the appropriate planning for a brownfield site, which could be beneficial to all stakeholders. The developed brownfield definition and index system can be used as a reference, and other researchers from different countries can use the same procedure to develop their definition and index system by adding or deleting some 
indicators. This research suggests that removing environmental contamination from the site is not the only way to deal with brownfield but well-structured and interdisciplinary planning is necessary to overcome redevelopment barriers.

Protecting the benefits of all stakeholders is a critical issue. Therefore, the federal government and local municipalities should adopt a consensus-based definition and implement the comprehensive evaluation index system to evaluate brownfield and expedite urban sustainable development. Financing dilemmas are often a barrier to such projects. Therefore, the relevant authorities should play a vital role in attracting investors locally and globally. Local citizens and the local government have key roles to play in the brownfield redevelopment process. Private investment should also be encouraged.

Moreover, public-private partnership (PPP) can be promoted to invest in brownfield sites. The government should also give out subsidies and incentives to investors and mandate a certain amount of investment from urban development projects. Although conflict can occur due to the involvement of multiple stakeholders, inter-government collaboration can expedite the decision-making process to achieve remediation objectives. The implications of this study are also significant for developing economies due to different sustainable development goals.

The current study is based on a survey of major stakeholders involved in the brownfield redevelopment process in Pakistan. These results are based on the perceptions of stakeholders, and measurement-based results can be different. Multi-group analysis can give more insights about different stakeholders. Moreover, the results of the current study, including the establishment of a standard brownfield definition and evaluation index system, can be verified in other developing countries. Analyzing barriers to brownfield redevelopment is a research project for the future. Brownfield risk assessment using different modern approaches and MCDM approaches is still underexplored. Effective utilization of renewable resources on brownfield sites is also advantageous but still uncovered in the literature. It is important to address barriers to renewable energy resources on brownfield sites due to the scarcity of energy resources in developing countries.

Author Contributions: Conceptualization, N.A. and M.W.; methodology, N.A., M.W., A.W.; software, N.A.; validation, N.A, Y.Z.; formal analysis, N.A., A.W.; investigation, Y.Z., M.I.; resources, Y.Z.; data curation, N.A., A.W.; writing-original draft preparation, M.I., M.W., A.W.; writing-review and editing, N.A., Y.Z.; visualization, M.I., A.W.; supervision, Y.Z.; project administration, Y.Z.; funding acquisition, Y.Z.

Funding: This research was funded by the Natural Science Foundation of Shaanxi Province, grant number 2017JM7002.

Acknowledgments: The brownfield research team acknowledges the support provided by the Natural Science Foundation of Shaanxi, China through the project "Research on Risk Allocation and Income Distribution Mechanism of Public-Private Partnership for Brownfield Regeneration Project" (2017JM7002).

Conflicts of Interest: The authors declare no conflict of interest.

\section{References}

1. Chen, Y.; Hipel, K.W.; Kilgour, D.M.; Zhu, Y. A strategic classification support system for brownfield redevelopment. Environ. Model. Softw. 2009, 24, 647-654. [CrossRef]

2. Filip, S.; Cocean, P. Urban industrial brownfields: Constraints and opportunities in Romania. Carpathian J. Earth Environ. Sci. 2012, 7, 155-164.

3. De Sousa, C. Brownfield redevelopment versus greenfield development: A private sector perspective on the costs and risks associated with brownfield redevelopment in the Greater Toronto Area. J. Environ. Plan. Manag. 2000, 43, 831-853. [CrossRef]

4. Dasgupta, S.; Tam, E.K.L. Environmental review: A comprehensive review of existing classification systems of brownfield sites. Environ. Pract. 2009, 11, 285-300. [CrossRef]

5. U.S Central Intelligence Agency. The World Factbook 2016; Central Intelligence Agency: Washington, DC, USA, 2016.

6. United Nations. Sustainable Development Knowledge Platform. Available online: https://sustainabledevel opment.un.org/sdgs (accessed on 20 March 2018). 
7. Kiani, K. Sustainable Development: How Far Has Pakistan Come and How Far Do We Have to Go? Available online: https:/ / www.dawn.com/news/1360165 (accessed on 10 July 2018).

8. Franz, M.; Pahlen, G.; Nathanail, P.; Okuniek, N.; Koj, A. Sustainable development and brownfield regeneration. What defines the quality of derelict land recycling? Environ. Sci. 2006, 3, 135-151. [CrossRef]

9. Pakistan Environmental Protection Agency. Acts, Ordinances, Rules and Regulations; Pakistan Environmental Protection Agency: Islamabad, Pakistan, 2016.

10. Alker, S.; Joy, V.; Roberts, P.; Smith, N. The definition of brownfield. J. Environ. Plan. Manag. 2000, 43, 49-69. [CrossRef]

11. Zhang, L.; Geng, Y.; Dong, H.; Zhong, Y.; Fujita, T.; Xue, B.; Park, H.-S. Emergy-based assessment on the brownfield redevelopment of one old industrial area: A case of Tiexi in China. J. Clean. Prod. 2016, 114, 150-159. [CrossRef]

12. Lesage, P.; Ekvall, T.; Deschênes, L.; Samoson, R. Environmental assessment of brownfield rehabilitation using two different life cycle inventory models. Int. J. Life Cycle Assess. 2007, 12, 497.

13. Wedding, G.C.; Crawford-Brown, D. Measuring site-level success in brownfield redevelopments: A focus on sustainability and green building. J. Environ. Manag. 2007, 85, 483-495. [CrossRef] [PubMed]

14. Wu, H.; Tiwari, P.; Han, S.S.; Chan, T.-K. Brownfield risk communication and evaluation. J. Prop. Res. 2017, 34, 233-250. [CrossRef]

15. Wang, Q.; Hipel, K.W.; Kilgour, D.M. Fuzzy real options in brownfield redevelopment evaluation. Adv. Decis. Sci. 2009, 2009. [CrossRef]

16. Morio, M.; Schädler, S.; Finkel, M. Applying a multi-criteria genetic algorithm framework for brownfield reuse optimization: Improving redevelopment options based on stakeholder preferences. J. Environ. Manag. 2013, 130, 331-346. [CrossRef] [PubMed]

17. Guo, P.; Liang, Y.-H.; Zhu, Y.-M. Multi-hierarchical Grey Evaluation of the Brownfield Redevelopment Project Based on Combinational Weight. Oper. Res. Manag. Sci. 2010, 5, 023.

18. BenDor, T.K.; Metcalf, S.S.; Paich, M. The dynamics of brownfield redevelopment. Sustainability 2011, 3, 914-936. [CrossRef]

19. Doick, K.; Sellers, G.; Castan-Broto, V.; Silverthorne, T. Understanding success in the context of brownfield greening projects: The requirement for outcome evaluation in urban greenspace success assessment. Urban For. Urban Green. 2009, 8, 163-178. [CrossRef]

20. Chrysochoou, M.; Brown, K.; Dahal, G.; Granda-Carvajal, C.; Segerson, K.; Garrick, N.; Bagtzoglou, A. A GIS and indexing scheme to screen brownfields for area-wide redevelopment planning. Landsc. Urban Plan. 2012, 105, 187-198. [CrossRef]

21. Schädler, S.; Finkel, M.; Bleicher, A.; Morio, M.; Gross, M. Spatially explicit computation of sustainability indicator values for the automated assessment of land-use options. Landsc. Urban Plan. 2013, 111, 34-45. [CrossRef]

22. Wang, B.; Ke, R.-Y.; Yuan, X.-C.; Wei, Y.-M. China's regional assessment of renewable energy vulnerability to climate change. Renew. Sustain. Energy Rev. 2014, 40, 185-195. [CrossRef]

23. Hou, D.; Al-Tabbaa, A.; Chen, H.; Mamic, I. Factor analysis and structural equation modelling of sustainable behaviour in contaminated land remediation. J. Clean. Prod. 2014, 84, 439-449. [CrossRef]

24. Zhu, Y.; Hipel, K.W.; Ke, G.Y.; Chen, Y. Establishment and optimization of an evaluation index system for brownfield redevelopment projects: An empirical study. Environ. Model. Softw. 2015, 74, 173-182. [CrossRef]

25. Zhu, Y.; Hipel, K.W.; Peng, G. A research framework for tackling brownfield problems in China using project management theory. In Proceedings of the 2008 IEEE International Conference on Systems, Man and Cybernetics, Singapore, 12-15 October 2008; pp. 3298-3303.

26. Dixon, T. Integrating sustainability into brownfield regeneration: Rhetoric or reality? -An analysis of the UK development industry. J. Prop. Res. 2006, 23, 237-267. [CrossRef]

27. Loures, L.; Vaz, E. Exploring expert perception towards brownfield redevelopment benefits according to their typology. Habitat Int. 2016, 72, 66-76. [CrossRef]

28. De Sousa, C.A. Turning brownfields into green space in the City of Toronto. Landsc. Urban Plan. 2003, 62, 181-198. [CrossRef]

29. Wang, L.; Fang, L.; Hipel, K.W. Negotiation over costs and benefits in brownfield redevelopment. Group Decis. Negot. 2011, 20, 509-524. [CrossRef] 
30. Loures, L. Post-industrial landscapes as drivers for urban redevelopment: Public versus expert perspectives towards the benefits and barriers of the reuse of post-industrial sites in urban areas. Habitat Int. 2015, 45, 72-81. [CrossRef]

31. Rizzo, E.; Pesce, M.; Pizzol, L.; Alexandrescu, F.M.; Giubilato, E.; Critto, A.; Marcomini, A.; Bartke, S. Brownfield regeneration in Europe: Identifying stakeholder perceptions, concerns, attitudes and information needs. Land Use Policy 2015, 48, 437-453. [CrossRef]

32. Loures, L.; Panagopoulos, T.; Burley, J.B. Assessing user preferences on post-industrial redevelopment. Environ. Plan. B Plan. Des. 2016, 43, 871-892. [CrossRef]

33. Tyman, S.K. Gunpowder Park: A Case Study of Post-Industrial Reinhabitation. Ph.D. Thesis, University of Oregon, Eugene, OR, USA, 2008.

34. USEPA (United States Environmental Protection Agency). Available online: https://www.epa.gov/brownf ields/overview-epas-brownfields-program (accessed on 23 March 2018).

35. De Sousa, C.A. Brownfield redevelopment in Toronto: An examination of past trends and future prospects. Land Use Policy 2002, 19, 297-309. [CrossRef]

36. Ferber, U.; Grimski, D.; Millar, K.; Nathanail, P. Sustainable Brownfield Regeneration: CABERNET Network Report; The Concerted Action on Brownfield and Economic Regeneration Network (CABERNET); CABERNET: Nottingham, UK, 2006.

37. CABERNET. Glossary of Terms for Holistic Management of Brownfield Regeneration. Available online: https:/ / www.cen.eu/work/areas/env/Pages/WS-74.aspx (accessed on 20 March 2018).

38. POST. A Brown and Pleasant Land; POST: London, UK, 1998.

39. Darmendrail, D. Pollution des Sols: Basol. 1999. Available online: http://basol.developpement-durable.go uv.fr/faq.htm\#q9 (accessed on 20 March 2018).

40. Freier, K. CLARINET Working Group 1: Brownfield Redevelopment Workplan; German Environmental Agency: Berlin, Germany, 1998.

41. Newton, P.W.J.B.E. Beyond greenfield and brownfield: The challenge of regenerating Australia's greyfield suburbs. Built Environ. 2010, 36, 81-104. [CrossRef]

42. Potts, L.; Cloete, C.E. Developing guidelines for brownfield development in South Africa. WIT Trans. Ecol. Environ. 2012, 162, 389-399.

43. Ekman, E.W. Strategies for Reclaiming Urban Postindustrial Landscapes. Ph.D. Thesis, Massachusetts Institute of Technology, Cambridge, MA, USA, 2004.

44. Franz, M.; Güles, O.; Prey, G. Place-Making and 'Green' Reuses of Brownfields in the Ruhr. Tijdschr. Voor Econ. Soc. Geogr. 2008, 99, 316-328. [CrossRef]

45. Tarawneh, D. Brownfield landscapes of Amman: Defining typologies of unnamed terrains. Transform. Urban Character Arab. Cities Since Late Last Century 2015, 90, 90.

46. Loures, L. Planning and Design in Postindustrial Land Transformation: East bank Arade River, Lagoa-Case Study. Ph.D. Thesis, University of Algarve, Faro, Portugal, 2011.

47. Zavadskas, E.K.; Turskis, Z.; Tamošaitiené, J.; Marina, V. Multicriteria selection of project managers by applying grey criteria. Technol. Econ. Dev. Econ. 2008, 14, 462-477. [CrossRef]

48. De, P.; Rawat, A. A fuzzy inventory model without shortages using triangular fuzzy number. Fuzzy Inf. Eng. 2011, 3, 59-68. [CrossRef]

49. Chang, C.-L.; Wei, C.-C.; Lee, Y.-H. Failure mode and effects analysis using fuzzy method and grey theory. Kybernetes 1999, 28, 1072-1080. [CrossRef]

50. NLUD-PDL. Previously-Developed Land that May Be Available for Development. Available online: https: / /www.gov.uk/government/statistics/national-land-use-database-of-previously-develope d-land-2012-nlud-pdl (accessed on 15 February 2018).

51. NRTEE. State of the Debate. Environmental Quality in Canadian Cities: The Federal Role. Available online: http:/ / webdocs.edmonton.ca/InfraPlan/Infra/Reports/environmental\%20cdn_cities_execsumma rry.pdf (accessed on 15 February 2018).

52. Bacot, H.; O'Dell, C. Establishing indicators to evaluate brownfield redevelopment. Econ. Dev. Q. 2006, 20, 142-161. [CrossRef]

53. Pediaditi, K.; Wehrmeyer, W.; Chenoweth, J. Sustainability Evaluation for Brownfield Redevelopment. In Proceedings of the Institution of Civil Engineers-Engineering Sustainability; Thomas Telford Ltd.: London, UK, 2006; pp. 3-10. 
54. Alexandrescu, F.M.; Pizzol, L.; Zabeo, A.; Rizzo, E.; Giubilato, E.; Critto, A. Identifying sustainability communicators in urban regeneration: Integrating individual and relational attributes. J. Clean. Prod. 2016, 173, 278-291. [CrossRef]

55. Laprise, M.; Lufkin, S.; Rey, E. An operational monitoring tool facilitating the transformation of urban brownfields into sustainable neighborhoods. Build. Environ. 2018, 142, 221-233. [CrossRef]

56. Laprise, M.; Lufkin, S.; Rey, E. An indicator system for the assessment of sustainability integrated into the project dynamics of regeneration of disused urban areas. Build. Environ. 2015, 86, 29-38. [CrossRef]

57. Limasset, E.; Pizzol, L.; Merly, C.; Gatchett, A.M.; Le Guern, C.; Martinát, S.; Klusáček, P.; Bartke, S. Points of attention in designing tools for regional brownfield prioritization. Sci. Total Environ. 2018, 622, 997-1008. [CrossRef] [PubMed]

58. Pizzol, L.; Zabeo, A.; Klusáček, P.; Giubilato, E.; Critto, A.; Frantal, B.; Martinát, S.; Kunc, J.; Osman, R.; Bartke, S. Timbre Brownfield Prioritization Tool to support effective brownfield regeneration. J. Environ. Manag. 2016, 166, 178-192. [CrossRef] [PubMed]

59. Yan, W.; Zhu, Y.; Ahmad, N. Theory of Inventive Problem Solving (TRIZ) based contradiction resolution strategies for Shaanxi Aviation Industrial Upgrading. In Proceedings of the 2016 IEEE International Conference on Industrial Engineering and Engineering Management (IEEM), Bali, Indonesia, 4-7 December 2016; pp. 1111-1115.

60. Lee, E.; Li, R.-J. Comparison of fuzzy numbers based on the probability measure of fuzzy events. Comput. Math. Appl. 1988, 15, 887-896. [CrossRef]

61. Deng, J. Grey System Theory and Applications; Geo-Li Publishing Co.: Taipei, Taiwan, 2000.

62. Rui, M.; Jiatai, Z. Research of hierarchy synthetic evaluation based on grey relational analysis. Syst. Eng. Theory Pract. 2008, 10, 019.

63. Rui, M.; Jiatai, Z. Research of hierarchy synthetic evaluation based on grey relational analysis. In Proceedings of the 2007 IEEE International Conference on Grey Systems and Intelligent Services, Nanjing, China, 18-20 November 2007; pp. 90-94.

64. Altherr, W.; Blumer, D.; Oldörp, H.; Nagel, P. How do stakeholders and legislation influence the allocation of green space on brownfield redevelopment projects? Five case studies from Switzerland, Germany and the UK. Bus. Strategy Environ. 2007, 16, 512-522. [CrossRef]

65. Novosák, J.; Hájek, O.; Nekolová, J.; Bednář, P. The spatial pattern of brownfields and characteristics of redeveloped sites in the Ostrava metropolitan area (Czech Republic). Morav. Geogr. Rep. 2013, 21, 36-45. [CrossRef]

66. Solitare, L. Prerequisite conditions for meaningful participation in brownfields redevelopment. J. Environ. Plan. Manag. 2005, 48, 917-935. [CrossRef] 